This article was published in Life Sciences, 128, 8-14, 2015

http://dx.doi.org/10.1016/j.lfs.2015.02.020

\title{
MicroRNA-21 expression and susceptibility to HPV-induced carcinogenesis - role of microenvironment in K14-HPV16 mice model
}

Isabel Paiva ${ }^{1,2}$, Rui M. Gil da $\operatorname{Costa}^{3,4}$, Joana Ribeiro ${ }^{1,5}$, Hugo Sousa ${ }^{1,5}$, Margarida Bastos $^{3}$, Ana Faustino-Rocha ${ }^{7}$, Carlos Lopes ${ }^{4}$, Paula A. Oliveira ${ }^{6,7}$, Rui Medeiros ${ }^{1,2,5,8,9}$

1. Molecular Oncology and Viral Pathology Group, CI-IPOP, Portuguese Institute of Oncology of Porto, Rua Dr. António Bernardino de Almeida, 4200-072 Porto, Portugal

2. ICBAS, Abel Salazar Institute for the Biomedical Sciences, University of Porto, Rua de Jorge Viterbo Ferreira 228, 4050-313, Porto, Portugal

3. LEPABE, Faculty of Engineering, University of Porto, Rua Dr. Roberto Frias s/n, 4200-465, Porto, Portugal

4. Experimental Pathology and Therapeutics Group, CI-IPOP, Portuguese Institute of Oncology, Rua Dr. António Bernardino de Almeida, 4200-072 Porto, Portugal

5. Virology Service, Portuguese Institute of Oncology of Porto, Rua Dr. António Bernardino de Almeida, 4200-072 Porto, Portugal

6. Veterinary Sciences Department, University of Trás-os-Montes and Alto Douro, UTAD, Quinta de Prados, 5001-801, Vila Real, Portugal

7. Center for the Research and Technology of Agro-Environmental and Biological Sciences (CITAB), University of Trás-os-Montes and Alto Douro, UTAD, Quinta de Prados, 5001-911, Vila Real, Portugal

8. CEBIMED, Faculty of Health Sciences of Fernando Pessoa University, Porto, Portugal

9. Portuguese League Against Cancer (Liga Portuguesa Contra o Cancro - Núcleo Regional do Norte), Estrada Interior da Circunvalação, nº657, 4200-177 Porto, Portugal

\section{*Corresponding author:}

Prof. Doutor Rui Medeiros

Instituto Português de Oncologia do Porto Francisco Gentil, EPE

Grupo de Oncologia Molecular e Patologia Viral - CI IPOP

Edifício Laboratórios Piso 4

Rua Dr. António Bernardino de Almeida, 4200-072 Porto

Telephone: +351 22508 4000; Fax: +351 225084001 .

E-mail: ruimedei@ipoporto.min-saude.pt

Word count: 4232

Figure count: 5

Table count: 2 


\section{ABSTRACT}

Human papillomaviruses (HPVs) are responsible for several types of cancer. K14-HPV16 transgenic mice express the HPV 16 early genes, developing multi-step carcinogenesis associated with marked inflammation, as observed in human patients. MicroRNAs (MiRNA) constitute a class of non-coding RNAs that regulate gene expression. In particular, miR-21 has been associated with carcinogenesis. However, little is known about this microRNA in the normal tissue microenvironment and its possible relationship with cancer predisposition. We hypothesized that miR-21 expression influences each tissue's susceptibility to HPV-induced carcinogenesis. In order to test this hypothesis, we evaluated miR-21 expression in ear and chest skin samples from 24-26 weeks old, female K14-HPV16 transgenic and wild-type mice. In wildtype mice (HPV-/-) miR-21 expression was lower in ear skin compared with chest skin ( $\mathrm{p}=0.036)$. Under the influence of HPV16 oncogenes, transgenic animals (HPV16+/-), developed in situ carcinoma in all ear samples and epidermal hyperplasia in chest samples. These results are consistent with the hypothesis that microRNA expression in the microenvironment of normal tissues may influence HPV-associated carcinogenesis. Furthermore, among transgenic animals, miR-21 expression was lower in in situ carcinoma samples compared with hyperplasia $(\mathrm{p}=0,043)$. This suggests that, despite the well-known role of miR-21 as an oncogene, its antiinflamatory and immunomodulatory properties may modulate HPV-induced carcinogenesis in a tissue-dependent manner. Further studies are warranted in order to explore the role of microRNAs in tissue susceptibility to carcinogenesis.

Keywords: K14-HPV16, miR-21, microenvironment, in situ carcinoma, hyperplasia 


\section{INTRODUCTION}

Human papillomavirus (HPV) infection is considered epidemic and may lead to the development of cancer. In fact, high-risk human papillomavirus, mainly HPV16 and HPV18, are the agents responsible for most cases of cervical cancer and a significant proportion of other types of cancer, such as anogenital and head and neck cancers (Major, Szarka, Sziklai, Gergely, \& Czegledy, 2005; Walboomers et al., 1999; Watson et al., 2008).The prevalence of cervical cancer and high mortality rates, especially in developing countries, is alarming and need immediate attention (Ferlay J, 2013).

K14-HPV16 transgenic mice are a particularly useful model for to study the development of HPVassociated squamous cell cancers. This model recapitulates multi-step carcinogenesis of uterine cervix and skin, starting with hyperplasia that progresses to dysplasia, in situ carcinoma (CIS) and, eventually, invasive carcinoma (Coussens, Hanahan, \& Arbeit, 1996). In this mouse model, the expression of HPV16 early region genes (E2-E8) is driven by the cytokeratin 14 (K14) promoter, specifically targeting epithelial basal cells (Coussens et al., 1996). Basal cells are mitotically active and thus may develop further mutations in response to a proliferative stimulus, and the expression of K14 has been shown to persist in well-differentiated squamous carcinomas (Stoler, Kopan, Duvic, \& Fuchs, 1988). Although several K14-HPV16 transgenic animals develop skin hyperplastic and/or dysplastic lesions in several inbred backgrounds, including C57BL/6, BALB/c, and SSIN/SENCAR, only mice backcrossed into the $\mathrm{FVB} / \mathrm{n}$ background progress to malignant squamous cell carcinomas of two pathological grades, welldifferentiated and moderate/poorly-differentiated, each displaying characteristic features of malignant behavior (Coussens et al., 1996). Squamous cell carcinomas are observed on $21 \%$ of animals aged 8 to 12 months, on the epidermis of the ear, the chest, and the truncal skin (Arbeit, Munger, Howley, \& Hanahan, 1994; Coussens et al., 1996; Herber, Liem, Pitot, \& Lambert, 1996; Song, Pitot, \& Lambert, 1999). The morphological and molecular similarities between this mouse model and human HPV-induced malignancies (Coussens et al., 1996), makes it a useful tool to study epigenetic and genetic factors that coordinate malignant conversion and regulate neoplastic progression.

MicroRNAs (miRNAs) are a class of endogenous small, non-coding RNA molecules of about 21 to 23 nucleotides that have the capacity to specifically inhibit translation or induce mRNA degradation, predominantly through targeting the $3^{\prime}$ untranslated regions (UTRs) of mRNA (Garzon, Calin, \& Croce, 2009). In normal cells, miRNAs control several processes including proliferation, differentiation and apoptosis. Because of their wide variety of targets, miRNAs have been found to affect numerous 
developmental processes within cells including hematopoietic lineage differentiation, immunity, inflammation, and tumorigenesis (Chen, 2005; Stahlhut Espinosa \& Slack, 2006).

MicroRNA-21 (miR-21) has been implicated in various aspects of carcinogenesis. In some cancers, miR21 is overexpressed and thus promotes cell proliferation and reduces apoptosis (Chan, Krichevsky, \& Kosik, 2005; Iyevleva et al., 2012; Kulda et al., 2010). Previous studies suggest that, as an oncogenic miRNA, miR-21 has a role not only in tumor growth but also in invasion and metastasis, by targeting multiple tumor/metastasis suppressor genes (Zhu et al., 2008). Recently, scientific community has started to debate whether miRNAs can be used as possible markers for the occurrence and development of the HPV-associated cancers (Ribeiro \& Sousa, 2014). However, in this cancers, the interplay between miR21 and HPV genes remain elusive and poorly understood. The tissue microenvironment is also responsible for miRNAs regulation, and may, in this way, play a role in neoplastic transformation (Whiteside, 2008).

In the present study, we aimed to analyzed miR-21 expression in skin samples with or without the presence of integrated HPV DNA and with different HPV-associated lesions. For this purpose, we have used K14-HPV16 transgenic mice, (Arbeit et al., 1994), to analyze miR-21 expression in ear and chest skin samples, evaluating its association with tissue microenvironment and predisposition to HPV-induced carcinogenesis. 


\section{MATERIAL AND METHODS}

\section{K14-HPV16 transgenic mice}

K14-HPV16 mice generation has been previously reported (Arbeit et al., 1994). K14-HPV16 mice on a FVB/n background were generously donated by Drs. Jeffrey Arbeit and Douglas Hanahan, from the University of California, through the USA National Cancer Institute Mouse Repository. After one week quarantine, the animals were maintained and bred in accordance with Portuguese (Portaria 1005/92 dated October the $23^{\text {rd }}$ ) and European (EU Directive 2010/63/EU) legislation, under controlled conditions of temperature $\left(23 \pm 2{ }^{\circ} \mathrm{C}\right)$, light-dark cycle $(12 \mathrm{~h} \mathrm{light} / 12 \mathrm{~h}$ dark) and relative humidity $(50 \pm 10 \%)$, using hardwood bedding. A standard diet (4RF21 GLP, Mucedola, Italy) and water were provided ad libitum, and health checks were performed daily. A total of 15 female mice from consecutive litters were selected for the study.

\section{Genotyping of HPV16-E6 and E2}

The mice were genotyped at weaning, using tail tip samples. To tissue lysis added $300 \mu \mathrm{L}$ of MagnaPure DNA Tissue Lysis Buffer (Roche®, Indianapolis, USA) and $20 \mu \mathrm{L}$ of Proteinase K. After, incubated overnight (16h) at $65{ }^{\circ} \mathrm{C}$. Nucleic acids were extracted using the High Pure Viral Nucleic Acid kit (Roche®, Indianapolis, USA) following the manufacturer's instructions. DNA purity was assessed by the ratio of the absorbance values at $260 / 280 \mathrm{~nm}$, using the NanoDrop® spectrophotometer v3.7 (Thermo Scientific, Wilmington DE, USA). The presence of amplifiable genomic DNA was tested by polymerase chain reaction (PCR) amplification of mouse $\beta$-globin using specific primers (Table 1) (Konkel, Tilghman, \& Leder, 1978). The PCR reaction was performed in a $50 \mu$ l solution with $1 \mathrm{x}$ Taq buffer, 2.0 mM MgCL2, $0.2 \mathrm{mM}$ DNTP'S, $0.50 \mu \mathrm{M}$ of each primer, $1 \mathrm{U}$ de Taq DNA Polimerase and $0.2 \mu \mathrm{g}$ of genomic DNA. The amplification conditions were as following: denaturation of DNA template at $94{ }^{\circ} \mathrm{C}$ for $3 \mathrm{~min}$, followed by 35 cycles at $94^{\circ} \mathrm{C}$ for $30 \mathrm{~s} 60^{\circ} \mathrm{C}$ for $45 \mathrm{~s}, 72{ }^{\circ} \mathrm{C}$ for $90 \mathrm{~s}$, and a final extension step at $72{ }^{\circ} \mathrm{C}$ for $10 \mathrm{~min}$. The amplified fragment of 494 base pairs (bp) was analyzed by electrophoresis in 1.5 $\%(w / v)$ agarose gels stained with ethidium bromide and visualized under UV light.

The integration of HPV was assessed by amplification of HPV16-E6 and HPV16-E2 genes with specific primers (Table 1), which amplify a region of $130 \mathrm{bp}$ and $184 \mathrm{bp}$, respectively, (adapted from a protocol described by Cañadas et al. and Ribeiro et al (Canadas et al., 2010; Ribeiro et al., 2014)). The PCR 
amplification reaction with HPV16-E6 and HPV16-E2 primers was carried in a $50 \mu 1$ reaction mixture with 1x PCR Buffer, $2.5 \mathrm{mM} \mathrm{MgCl2}, 0.2 \mathrm{mM}$ DNTP'S, $0.30 \mu \mathrm{M}$ of each primer, $1 \mathrm{U}$ of Taq DNA polymerase and $0.2 \mu \mathrm{g}$ of genomic DNA. Thermal cycling was performed as follows: initial denaturation of DNA template at $94{ }^{\circ} \mathrm{C}$ for $2 \mathrm{~min}$, followed by 35 cycles at $94{ }^{\circ} \mathrm{C}$ for $1 \mathrm{~min}, 60{ }^{\circ} \mathrm{C}$ for $1 \mathrm{~min}$, and $72{ }^{\circ} \mathrm{C}$ for $1 \mathrm{~min}$ and a final extension step at $72{ }^{\circ} \mathrm{C}$ for $5 \mathrm{~min}$. The amplified fragment was analyzed by electrophoresis in $1.5 \%(\mathrm{w} / \mathrm{v})$ agarose gels stained with ethidium bromide and visualized under UV light.

The resulting genotypes were compared with the respective phenotypes.

Table 1 - Primer sequences

$\begin{array}{lll}\text { Target/Name } & \text { Amplicon } & \text { Sequence } \\ \text { Mouse } \boldsymbol{\beta} \text {-globin } & & \\ \text { MBG_fwd } & 494 \mathrm{bp} & \text { 5'-CCAATCTGCTCACACAGGATAGAGAGGGCAGG-3', } \\ \text { MBG_rev } & & \text { 5'-CCTTGAGGCTGTCCAAGTGATTCAGGCCATCG-3', }\end{array}$

\section{HPV16-E6}

HPV16_E6fwd 130 bp

5'-AAAGCCACTGTGTCCTGA-3'

HPV16_E6rev

5'-CTGGGTTTCTCTACGTGTTTC-3'

\section{HPV16-E2}

HPV16_E2fwd $184 \mathrm{bp}$

5'-TTTAGCAGCAACGAAGTATCC-3'

HPV16_E2rev

\section{Sample collection}

Eight hemizygous (+/-) and seven wild-type (-/-) females were sacrificed at 24 to 28 weeks of age by using sodium pentobarbital followed by intracardiac punction and exsanguination, as indicated by the Federation for Laboratory Animal Science Associations (FELASA). Ear and chest skin samples from each animal (13 samples from transgenic and 14 samples from wild-type animals) were collected into TriPure reagent (Roche® Applied Science), macerated, and kept at $-80{ }^{\circ} \mathrm{C}$ until processing. Matched samples were collected into $10 \%$ neutral buffered formalin for routine histological processing. 
Histological sections $(2 \mu$ m-thick) were stained with haematoxylin and eosin $(\mathrm{H} \& \mathrm{E})$ for examination on light microscopy. Samples were classified as normal skin, epidermal hyperplasia and epidermal CIS by two independent researchers (CL and RGC), as previously described (Arbeit et al., 1994). In order to analyse tumour-associated inflammatory cell infiltration, leukocytes were counted in the neighbouring dermis. Total leukocytes and each leukocytic population were assessed in 3 adjacent high power fields and expressed as the mean \pm standard deviation.

\section{Analysis of miRNA expression}

Extraction of total RNA from samples preserved in TriPure reagent was performed using the High Pure Viral Nucleic Acid kit (Roche®, Indianapolis, USA), according to manufacturer's instructions. RNA quality was assessed using NanoDrop® spectrophotometer v3.7 (Thermo Scientific, Wilmington DE, USA).

Hsa-miR-21_000397 and snoRNA-202_001232 were analyzed using two-step real-time PCR protocols with TaqMan® MicroRNA Assays (Applied Biosystems, Foster CA, USA). The conversion of miRNA to cDNA was performed using TaqMan® MicroRNA Reverse Transcription Kit (Applied Biosystems®, Foster CA, USA) in a $15 \mu \mathrm{L}$ of total volume reaction mix with: $7 \mu \mathrm{L}$ of a master mix containing $1 \mathrm{x}$ RT buffer, 1.0 mM of total dNTPs, 50U MultiScribe Reverse Transcriptase Enzyme and 0.25U of RNase inhibitor; $3 \mu \mathrm{L}$ of RT primers (Applied Biosystems, Foster CA, USA); and $5 \mu \mathrm{L}$ of RNA sample. The amplification conditions were as follows: $30 \mathrm{~min}$ at $15^{\circ} \mathrm{C}, 52 \mathrm{~min}$ at $42{ }^{\circ} \mathrm{C}$ and finally $10 \mathrm{~min}$ at $85^{\circ} \mathrm{C}$. All reverse transcriptase reactions included two non-template controls using double distilled water to replace template RNA.

qPCRs were performed on a StepOne Real-time PCR System (Applied Biosystems, Foster CA, USA) with a $20 \mu$ f final volume: $1 \times$ TaqMan ${ }^{\circledR}$ Universal PCR Master Mix II (Applied Biosystems, Foster City, California USA); 1x MicroRNA Assay (Applied Biosystems, Foster City, California USA); and $2 \mu \mathrm{L}$ cDNA from RT snoRNA-202 was used as endogenous control. Thermal cycling conditions were: 10 min at $95{ }^{\circ} \mathrm{C}$ followed by 45 cycles of $15 \mathrm{~s}$ at $95^{\circ} \mathrm{C}$ and $1 \mathrm{~min}$ at $60{ }^{\circ} \mathrm{C}$. All reactions included two-template controls using double distilled water to replace template cDNA. 


\section{Statistical Analysis}

Data analysis was performed using the software IBM®SPSS ®Statistics for Windows (Version 20.0). The T-Student test was used in order to evaluate any statistical differences in the normalized expression of the miR-21. In order to analyze the normalized relative expression $(-\Delta \mathrm{Ct})$ of the different groups, we considered the results corresponding to a $99 \%$ representation of the population ( $\bar{X} \pm 2 \mathrm{SD}$ ).

\section{RESULTS}

\section{Analysis of genotyping vs phenotyping and tumour-associated inflammatory cell infiltration}

In 8 out of 15 mice we observed the presence of HPV16 integration (Figure 1). All animals with integrated HPV16 DNA presented a phenotype characteristic of HPV-associated lesions, as persistent epidermal squamous hyperplasia in various degrees and hyperkeratosis, as previously described (Arbeit et al., 1994) (Figure 2). Wild-type mice did not develop any skin lesions. Also, we observed in histologic evaluation that in all cases with integrated HPV16 DNA, the chest skin presented epidermal hyperplasia while the ear skin showed CIS. Wild-type mice presented, as expected, normal skin histology (Figure 3).

HPV-transgenic mice showed increased numbers of tumour-associated leukocytes compared with wild-type animals (Table 2). Ear skin (presenting with CIS) showed increased inflammatory cell infiltration Mainly neutrophils) when compared with chest skin (hyperplasia). From the analysis of tumour-associated inflammatory cell infiltration, we observed that there is an increase in the number of leukocytes in the inflammatory infiltrate of CIS comparatively with tissue that showed hyperplasia. The normal histology of chest and ear tissue presented fewer leukocytes compared to tissue with hyperplasia and CIS. (Table 2)
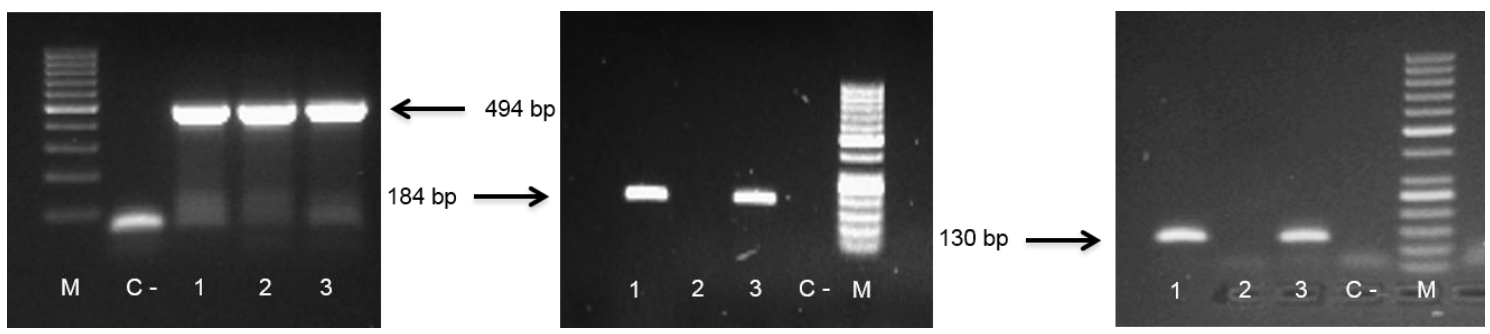

Fig. 1 Genotyping of HPV16-E6 and E2 in mice. The presence of integrated HPV was assessed by amplification of HPV-E2 (b) and HPV-E6 (c) genes by polymerase chain 
reaction methodology (PCR) in-house. Samples 1 and 3 are HPV+; sample 2 is HPV-. Mouse- $\beta$-globin gene was used as endogenous control (a). M: molecular weight size marker: (a)100 bp, (b,c)50 bp; C-: negative control
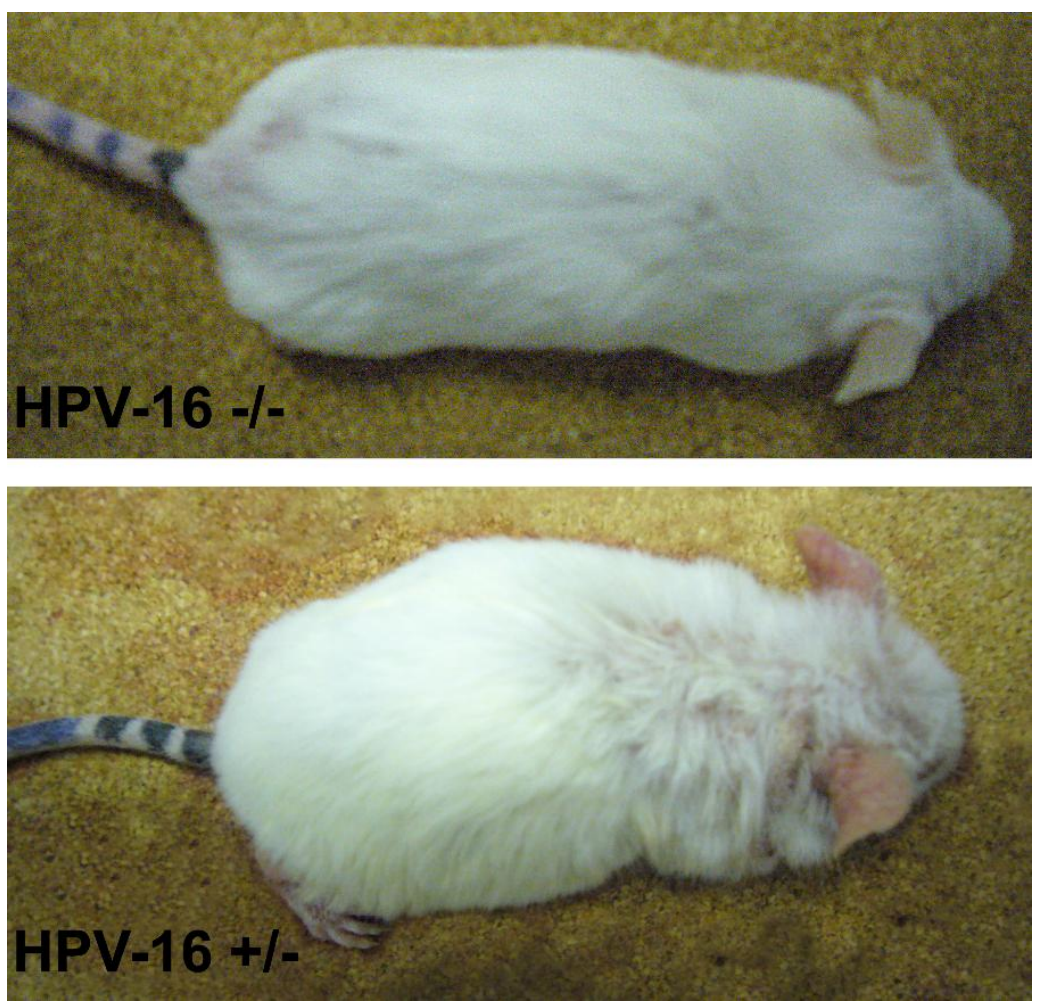

Fig. 2 Wild-type (HPV16 -/-) and K14-HPV16 transgenic (HPV16 +/-) mice. Transgenic mice show a hunched position, partial thoracic and cephalic alopecia, together with extensive hyperkeratosis and auricular erythema. 


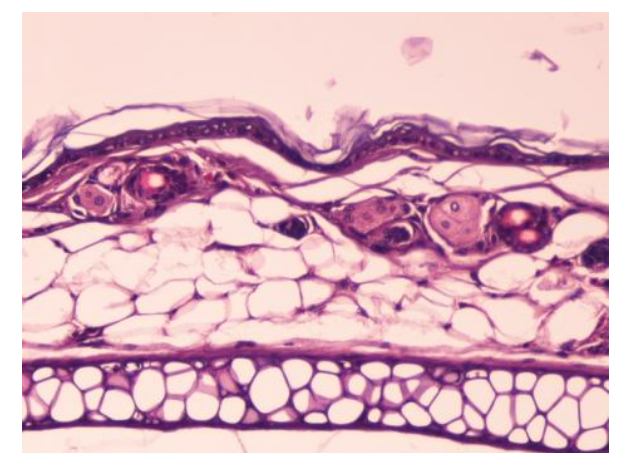

a)

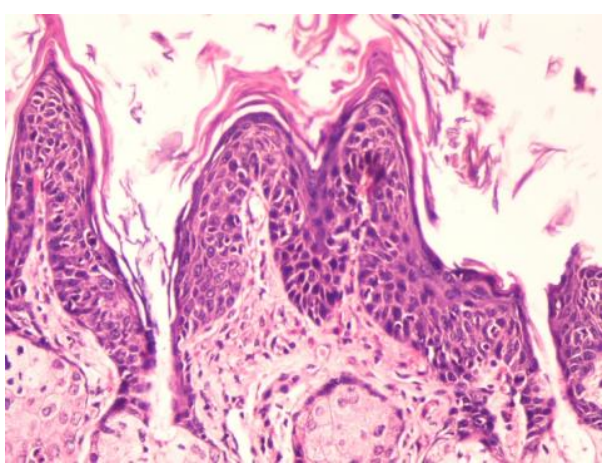

b)

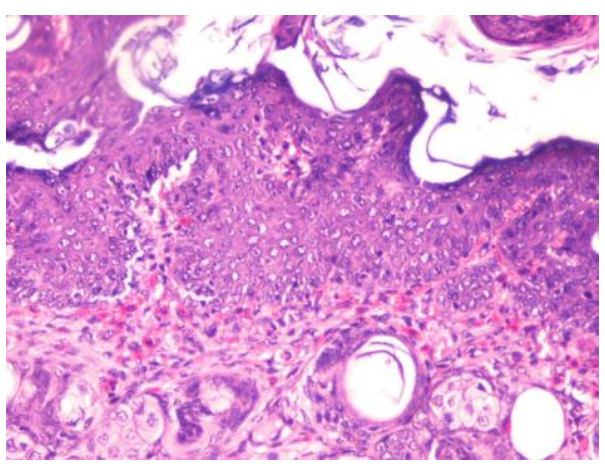

c)

Fig. 3 a) Wild-type (-/-) female FVB/n mouse. Chest skin showing normal histology. H\&E, 200x bar=50 $\mu \mathrm{m}$ b) K14-HPV16 transgenic (+/-) female FVB/n mouse. Chest skin showing epidermal hyperplasia and orthokeratotic hyperkeratosis. Note increased number of epidermal strata with conserved orderly squamous differentiation. c) K14-HPV16 transgenic (+/-) female FVB/n mouse. Ear skin showing in situ carcinoma. Note loss of epidermal stratification and progressive differentiation, presence of suprabasal mitotic figures and anisocytosis and abrupt parakeratotic keratinization with hyperkeratosis. The underlying stroma exhibits intense mixed inflammatory cell infiltration and neovascularization. 
Table 2. Tumour-associated inflammatory cell infiltration in HPV16 -/- and HPV16 +/- mice. Total leukocytes and each leukocytic population were assessed in 3 adjacent high power fields and expressed as the mean \pm standard deviation.

\begin{tabular}{|c|c|c|c|c|c|c|c|c|}
\hline Genotype & Tissue & Histology & Macrophages & Neutrophils & Lymphocytes & Mast cells & Plasma cells & $\begin{array}{c}\text { Total } \\
\text { leukocytes }\end{array}$ \\
\hline \multirow{2}{*}{ HPV16 -/- } & chest & normal & $0,5 \pm 0,4$ & $0,1 \pm 0,1$ & $0,1 \pm 0,3$ & $1,5 \pm 0,5$ & $0,2 \pm 0,3$ & $2,3 \pm 0,7$ \\
\hline & ear & normal & $0,6 \pm 0,4$ & $0,1 \pm 0,1$ & $1,1 \pm 0,3$ & $1,9 \pm 0,5$ & $0 \pm 0,2$ & $3,4 \pm 0,8$ \\
\hline \multirow{2}{*}{ HPV16 +/- } & chest & hyperplasia & $6,6 \pm 3,5$ & $3,6 \pm 2,7$ & $4,3 \pm 3,7$ & $5,5 \pm 2,3$ & $2,2 \pm 1,2$ & $22,1 \pm 2,9$ \\
\hline & ear & $\mathrm{CIS}$ & $44,8 \pm 10,6$ & $138,7 \pm 122,5$ & $11,8 \pm 10,51$ & $22,5 \pm 16,9$ & $0,3 \pm 0,5$ & $218,2 \pm 113,0$ \\
\hline
\end{tabular}

MiRNA-21 expression profile in skin tissues from wild-type mice

We quantified the miR-21 expression in normal skin tissues (wild-type mice) and we verified that the ear tissues presented lower expression levels compared with chest tissues $(p=0.036)$ (Figure 4a).

\section{MiRNA-21 expression profile in skin tissues of transgenic mice}

To evaluate the miR-21 expression in tissues from transgenic mice, we analyzed ear and chest skin samples. Similarly to that detected in wild-type mice, we observed lower expression levels of miR-21 in ear tissues (histologically presenting with CIS) when compared with chest tissue (histologically presenting with epidermal hyperplasia) ( $p=0.043)$ (Figure $4 b)$. 


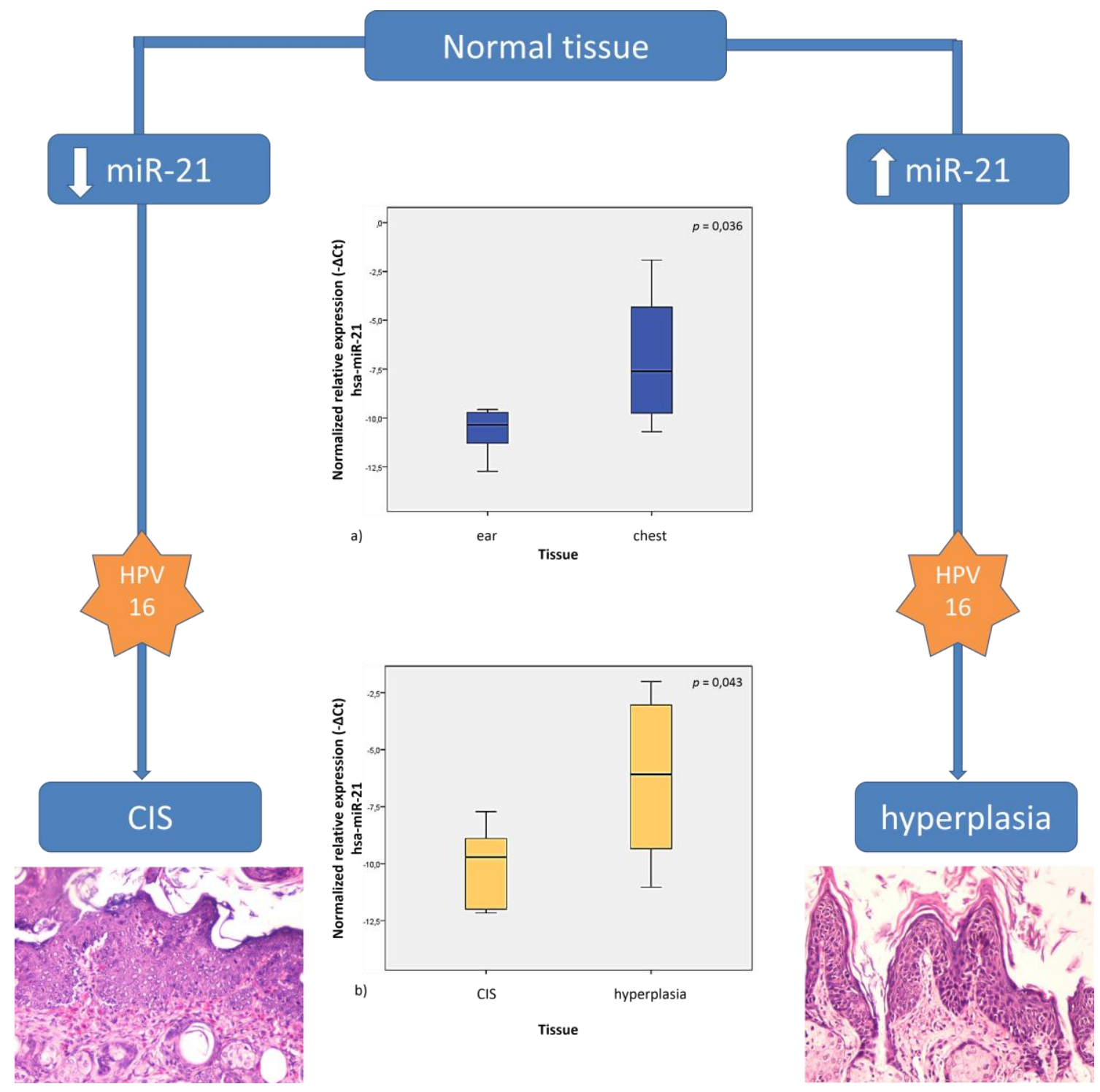

Fig. 4 Normalized relative expression of miR-21 in ear and chest normal tissue (a). Normalized expression of miR-21 in different lesions of K14-HPV16 transgenic mice (CIS and hyperplasia) (b).

\section{MiRNA-21 expression profile in tissue of transgenic versus wild-type mice}

To investigate a possible direct influence of HPV16 on the miR-21 expression profile, we compared the relative expression between tissues (ear and chest) of transgenic mice and wild-type mice. Our data showed no statistical significant difference in miR-21 expression levels between both groups $(p=0.615)$. Identically, no differences were found when we compared miR-21 expression in ear $(p=0.486)$ and chest ( $p=0.731$ ) samples, separately, between transgenic and wild type mice (Figure 5). 

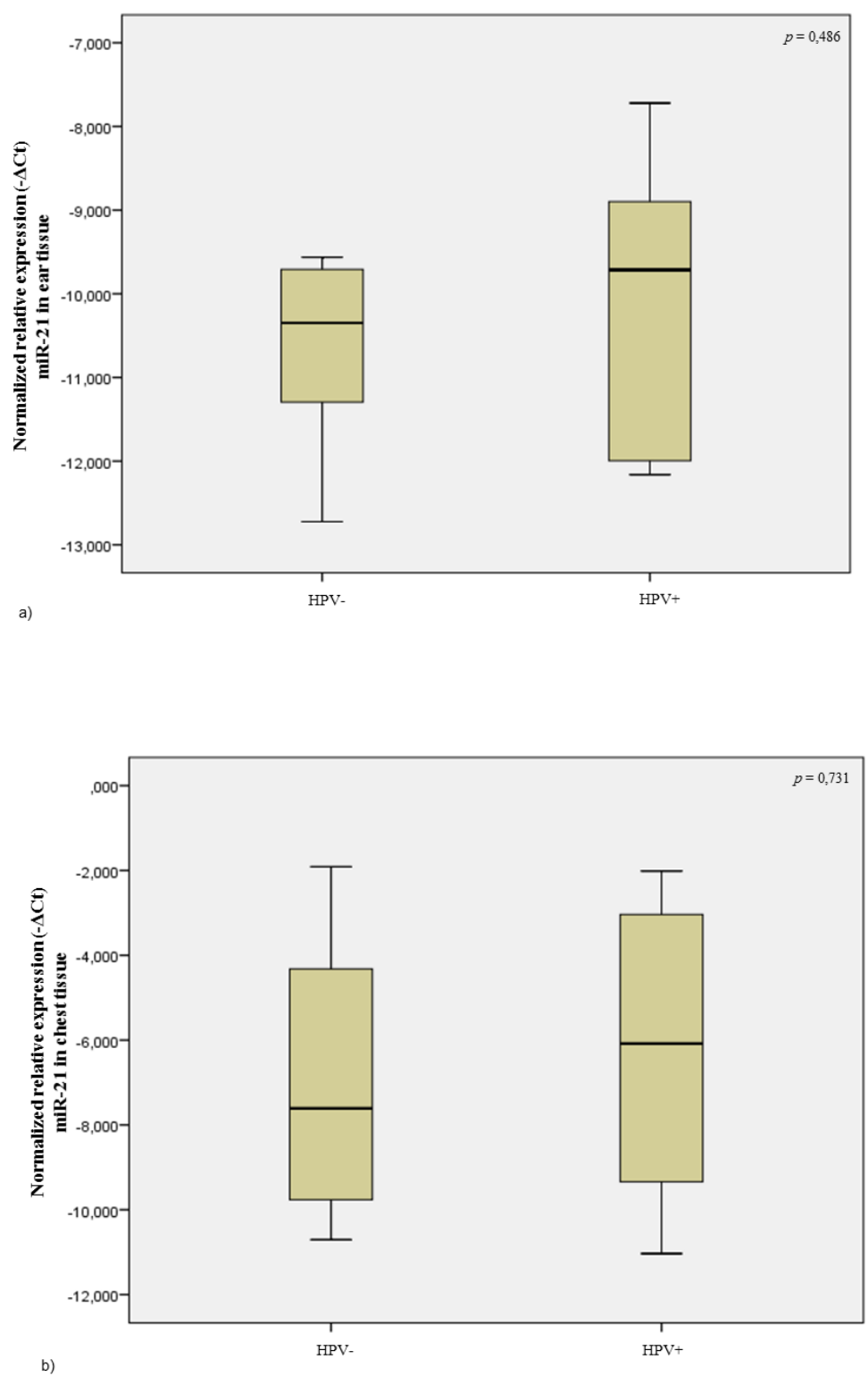

Fig. 5 Normalized relative expression of miR-21 in transgenic mice (HPV+) and wild-type mice (HPV-), in ear (a) and chest tissue (b). 


\section{DISCUSSION}

The elucidation of the importance of miRNAs in tumor biology is a rapidly growing field in oncology research, because it holds promise for disease prognosis and targets for the development of novel cancer therapeutics (Garzon, Marcucci, \& Croce, 2010; Nelson \& Weiss, 2008).

MiR-21 is a highly overexpressed miRNA in several cancers. Its overexpression has been observed in head and neck, cervical, ovarian, lung, liver, stomach and pancreatic cancers (Guo et al., 2009; Hui et al., 2010; Jiang et al., 2008; Lee et al., 2007; T. Yao \& Lin, 2012; Zhang et al., 2010). Previous studies indicate that HPV infection is the main factor driving the transition from normal cervical epithelium to cervical preneoplastic lesions, intraepithelial neoplasia and, successively, to invasive cervical cancer (Bosch \& de Sanjose, 2007; zur Hausen, 2002). The influence of others factors, such as the host microenvironment, remains poorly understood. In particular, no conclusive evidence exists concerning the relation between HPV and miR-21 expression in cervical cancer, the most important HPV-associated tumor.

K14-HPV16 transgenic mice are a useful experimental model for studying HPV-induced carcinogenesis. The FVB/n mouse strain is particularly prone to HPV-driven carcinogenesis, as other mouse strains (e.g. Balb/c, C57B1/6, SSIN/SENCAR) bearing an identical transgene, failed to develop invasive carcinomas (Coussens et al., 1996). This observation highlights the key role of host factors in the development of HPV-associated tumors.

Our results indicate that, among wild-type mice (HPV-/-), the expression of miR-21 is lower in ear skin tissue compared with chest skin $(p=0.036)$. Furthermore, in matched $24-26$ weeks-old transgenic animals (HPV16+/-), we found that CIS had developed in all ear skin samples, whereas chest skin samples only showed epidermal hyperplasia. Consistently, in these samples, miR-21 expression was lower in CIS (ear skin) samples when compared to hyperplasia (chest skin) $(p=0,043)$. We conclude that the expression of miR-21 in normal tissues could be an important factor in the local microenvironment favoring the development of HPV-associated tumors.

Several studies have expanded the concept that inflammation is a critical component of tumor progression, including HPV-associated tumors (Boccardo, Lepique, \& Villa, 2010). Many cancers arise from sites of infection, chronic irritation and inflammation (Coussens \& Werb, 2002). Among other phenomena, inflammation promotes stromal remodeling and inflammatory cell infiltration (Neuchrist et 
al., 1990; Ortegel, Staren, Faber, Warren, \& Braun, 2000), including monocytes/macrophages, B and T lymphocytes, NK cells, and neutrophils. Our results confirm that tumour progression is accompanied by increased inflammatory cell infiltration, especially macrophages and neutrophils. In our study we found that there is an increased of inflammation with tumor progression by infiltration of leucocytes especciphyges and neutrophils. In K14-HPV16 transgenic mice, a deficiency in CD4+ $\mathrm{T}$ cells has been previously shown to modulate inflammation, delaying neoplastic progression and lowering tumor incidence (Daniel et al., 2003).

Considerable evidence indicates that miR-21 has anti-inflammatory properties. Previous studies reported that miR-21 silences the pro-inflammatory interleukin 12 (IL-12) (Lu et al., 2011). IL-12 is a major cytokine that regulates Th1 versus Th2 decisions, primarily by inducing $\mathrm{T}$ cells to produce the Th1 cytokine IFN- $\gamma$ (Gately et al., 1998), leading to enhanced inflammation and tumor progression. Other studies demonstrated that elevated levels of several pro-inflammatory, type-1 interleukins, like Il-12, were indicators of cervical HPV persistence, underscoring the potential negative biological effects of puflkongeation (Scott et al., 2013). Our results are in accordance with these reports, suggesting that high levels of miR-21 may decrease inflammation, possibly by interacting with Il-12 and, thus, reduce eountering malignant transformation.

Furthermore, IL-1 $\beta$ is a target of miR-21 and this cytokine has an important role in inflammation (Apte \& Voronov, 2008). This is a pro-inflammatory cytokine associated with stimulation of the tumor microenvironment in favor of increased cell proliferation and tissue angiogenesis (Voronov et al., 2003). These results are consistent with our findings, suggesting that low levels of miR-21 may be associated with high levels of Il-1 $\beta$, thus promoting the increase of inflammation and, consequently, the carcinogenic process.

Programmed cell death 4 (PDCD4), a tumor suppressor gene, is an important functional target of the miR-21 in several cancers, including in cervical cancers (Q. Yao, Xu, Zhang, Zhou, \& Qu, 2009). This target is a pro-inflammatory protein that promotes activation of the transcription factor NF-kB and suppresses the anti-inflammatory interleukin 10 (IL-10). Some studies observed that miR-21 directly blocked NF-kB activity and promoted IL-10 production (Sheedy et al., 2010). NF-kB can act as an oncogene through its ability to stimulate inflammation, cell proliferation and survival. NF-kB is constitutively activated in several human cancers (Li, Withoff, \& Verma, 2005), including cervical cancer 
(Branca et al., 2006; Nair, Venkatraman, Maliekal, Nair, \& Karunagaran, 2003) and has been proposed to be an important link between chronic inflammation and cancer (Karin, 2009). In our study, low levels of miR-21 may promote NF-kB activation, through of PDCD4 expression, and, thus, increase the predisposition to cancer development.

\section{Conclusion}

Previous data correlating miR-21 downregulation with increased inflammation, may explain our findings suggesting that tissues with lower miR-21 expression are more prone to cancer progression. These findings are important in the quest to gauge the utility of miR-21 expression in evaluation of tissues with higher predisposition to cancer development.

\section{Acknowledgments}

Rui M. Gil da Costa is supported by grant SFRH/BPD/85462/2012 from the Portuguese Foundation for Science and Technology, financed by the Portuguese Government and the Social European Fund.

Conflict of interest: The authors declare that they have no conflict of interest. 


\section{REFERENCES}

Apte, R. N., \& Voronov, E. (2008). Is interleukin-1 a good or bad 'guy' in tumor immunobiology and immunotherapy? Immunol Rev, 222, 222-241. doi: 10.1111/j.1600065X.2008.00615.X

Arbeit, J. M., Munger, K., Howley, P. M., \& Hanahan, D. (1994). Progressive squamous epithelial neoplasia in K14-human papillomavirus type 16 transgenic mice. $J$ Virol, 68(7), 4358-4368.

Boccardo, E., Lepique, A. P., \& Villa, L. L. (2010). The role of inflammation in HPV carcinogenesis. Carcinogenesis, 31(11), 1905-1912. doi: 10.1093/carcin/bgq176

Bosch, F. X., \& de Sanjose, S. (2007). The epidemiology of human papillomavirus infection and cervical cancer. Dis Markers, 23(4), 213-227.

Branca, M., Giorgi, C., Ciotti, M., Santini, D., Di Bonito, L., Costa, S., . . Syrjanen, K. (2006). Upregulation of nuclear factor-kappaB (NF-kappaB) is related to the grade of cervical intraepithelial neoplasia, but is not an independent predictor of high-risk human papillomavirus or disease outcome in cervical cancer. Diagn Cytopathol, 34(8), 555563. doi: $10.1002 / \mathrm{dc} .20514$

Canadas, M. P., Darwich, L., Sirera, G., Cirigliano, V., Bofill, M., Clotet, B., \& Videla, S. (2010). New molecular method for the detection of human papillomavirus type 16 integration. Clin Microbiol Infect, 16(7), 836-842. doi: 10.1111/j.14690691.2009.02964.x

Chan, J. A., Krichevsky, A. M., \& Kosik, K. S. (2005). MicroRNA-21 is an antiapoptotic factor in human glioblastoma cells. Cancer Res, 65(14), 6029-6033. doi: 10.1158/00085472.can-05-0137

Chen, C. Z. (2005). MicroRNAs as oncogenes and tumor suppressors. N Engl J Med, 353(17), 1768-1771. doi: 10.1056/NEJMp058190

Coussens, L. M., Hanahan, D., \& Arbeit, J. M. (1996). Genetic predisposition and parameters of malignant progression in K14-HPV16 transgenic mice. Am J Pathol, 149(6), 18991917.

Coussens, L. M., \& Werb, Z. (2002). Inflammation and cancer. Nature, 420(6917), 860-867. doi: 10.1038 /nature 01322

Daniel, D., Meyer-Morse, N., Bergsland, E. K., Dehne, K., Coussens, L. M., \& Hanahan, D. (2003). Immune enhancement of skin carcinogenesis by CD4+ T cells. J Exp Med, 197(8), 1017-1028. doi: 10.1084/jem.20021047

Ferlay J, S. I., Ervik M, Dikshit R, Eser S, Mathers C, Rebelo M, Parkin DM, Forman D, Bray, F. (2013). Cancer Incidence and Mortality Worldwide: IARC CancerBase No. 11. from http://globocan.iarc.fr

Garzon, R., Calin, G. A., \& Croce, C. M. (2009). MicroRNAs in Cancer. Annu Rev Med, 60, 167-179. doi: 10.1146/annurev.med.59.053006.104707

Garzon, R., Marcucci, G., \& Croce, C. M. (2010). Targeting microRNAs in cancer: rationale, strategies and challenges. Nat Rev Drug Discov, 9(10), 775-789. doi: 10.1038/nrd3179

Gately, M. K., Renzetti, L. M., Magram, J., Stern, A. S., Adorini, L., Gubler, U., \& Presky, D. H. (1998). The interleukin-12/interleukin-12-receptor system: role in normal and pathologic immune responses. Annu Rev Immunol, 16, 495-521. doi: 10.1146/annurev.immunol.16.1.495

Guo, J., Miao, Y., Xiao, B., Huan, R., Jiang, Z., Meng, D., \& Wang, Y. (2009). Differential expression of microRNA species in human gastric cancer versus non-tumorous tissues. J Gastroenterol Hepatol, 24(4), 652-657. doi: 10.1111/j.1440-1746.2008.05666.x

Herber, R., Liem, A., Pitot, H., \& Lambert, P. F. (1996). Squamous epithelial hyperplasia and carcinoma in mice transgenic for the human papillomavirus type $16 \mathrm{E} 7$ oncogene. $J$ Virol, 70(3), 1873-1881.

Hui, A. B., Lenarduzzi, M., Krushel, T., Waldron, L., Pintilie, M., Shi, W., . . Liu, F. F. (2010). Comprehensive MicroRNA profiling for head and neck squamous cell carcinomas. Clin Cancer Res, 16(4), 1129-1139. doi: 10.1158/1078-0432.ccr-09-2166 
Iyevleva, A. G., Kuligina, E., Mitiushkina, N. V., Togo, A. V., Miki, Y., \& Imyanitov, E. N. (2012). High level of miR-21, miR-10b, and miR-31 expression in bilateral vs. unilateral breast carcinomas. Breast Cancer Res Treat, 131(3), 1049-1059. doi: 10.1007/s10549-011-1845-Z

Jiang, J., Gusev, Y., Aderca, I., Mettler, T. A., Nagorney, D. M., Brackett, D. J., . . . Schmittgen, T. D. (2008). Association of MicroRNA expression in hepatocellular carcinomas with hepatitis infection, cirrhosis, and patient survival. Clin Cancer Res, 14(2), 419-427. doi: 10.1158/1078-0432.ccr-07-0523

Karin, M. (2009). NF-kappaB as a critical link between inflammation and cancer. Cold Spring Harb Perspect Biol, 1(5), a000141. doi: 10.1101/cshperspect.a000141

Konkel, D. A., Tilghman, S. M., \& Leder, P. (1978). The sequence of the chromosomal mouse beta-globin major gene: homologies in capping, splicing and poly(A) sites. Cell, 15(4), $1125-1132$.

Kulda, V., Pesta, M., Topolcan, O., Liska, V., Treska, V., Sutnar, A., . . . Cerny, R. (2010). Relevance of miR-21 and miR-143 expression in tissue samples of colorectal carcinoma and its liver metastases. Cancer Genet Cytogenet, 200(2), 154-160. doi: 10.1016/j.cancergencyto.2010.04.015

Lee, E. J., Gusev, Y., Jiang, J., Nuovo, G. J., Lerner, M. R., Frankel, W. L., . . Schmittgen, T. D. (2007). Expression profiling identifies microRNA signature in pancreatic cancer. Int J Cancer, 120(5), 1046-1054. doi: 10.1002/ijc.22394

Li, Q., Withoff, S., \& Verma, I. M. (2005). Inflammation-associated cancer: NF-kappaB is the lynchpin. Trends Immunol, 26(6), 318-325. doi: 10.1016/j.it.2005.04.003

Lu, T. X., Hartner, J., Lim, E. J., Fabry, V., Mingler, M. K., Cole, E. T., . . Rothenberg, M. E. (2011). MicroRNA-21 limits in vivo immune response-mediated activation of the IL12/IFN-gamma pathway, Th1 polarization, and the severity of delayed-type hypersensitivity. J Immunol, 187(6), 3362-3373. doi: 10.4049/jimmunol.1101235

Major, T., Szarka, K., Sziklai, I., Gergely, L., \& Czegledy, J. (2005). The characteristics of human papillomavirus DNA in head and neck cancers and papillomas. J Clin Pathol, 58(1), 51-55. doi: 10.1136/jcp.2004.016634

Nair, A., Venkatraman, M., Maliekal, T. T., Nair, B., \& Karunagaran, D. (2003). NF-kappaB is constitutively activated in high-grade squamous intraepithelial lesions and squamous cell carcinomas of the human uterine cervix. Oncogene, 22(1), 50-58. doi: 10.1038/sj.onc. 1206043

Nelson, K. M., \& Weiss, G. J. (2008). MicroRNAs and cancer: past, present, and potential future. Mol Cancer Ther, 7(12), 3655-3660. doi: 10.1158/1535-7163.mct-08-0586

Neuchrist, C., Grasl, M., Scheiner, O., Lassmann, H., Ehrenberger, K., \& Kraft, D. (1990). Squamous cell carcinoma: infiltrating monocyte/macrophage subpopulations express functional mature phenotype. Br J Cancer, 62(5), 748-753.

Ortegel, J. W., Staren, E. D., Faber, L. P., Warren, W. H., \& Braun, D. P. (2000). Cytokine biosynthesis by tumor-infiltrating $\mathrm{T}$ lymphocytes from human non-small-cell lung carcinoma. Cancer Immunol Immunother, 48(11), 627-634.

Ribeiro, J., \& Sousa, H. (2014). MicroRNAs as biomarkers of cervical cancer development: a literature review on miR-125b and miR-34a. Mol Biol Rep, 41(3), 1525-1531. doi: 10.1007/s11033-013-2998-0

Ribeiro, J., Teixeira, D., Marinho-Dias, J., Monteiro, P., Loureiro, J., Baldaque, I., . . Sousa, H. (2014). Characterization of human papillomavirus genotypes and HPV-16 physical status in cervical neoplasias of women from northern Portugal. Int J Gynaecol Obstet, 125(2), 107-110. doi: 10.1016/j.ijgo.2013.10.011

Scott, M. E., Shvetsov, Y. B., Thompson, P. J., Hernandez, B. Y., Zhu, X., Wilkens, L. R., . . Goodman, M. T. (2013). Cervical cytokines and clearance of incident human papillomavirus infection: Hawaii HPV cohort study. Int J Cancer, 133(5), 1187-1196. doi: 10.1002/ijc. 28119

Sheedy, F. J., Palsson-McDermott, E., Hennessy, E. J., Martin, C., O'Leary, J. J., Ruan, Q., . . O'Neill, L. A. (2010). Negative regulation of TLR4 via targeting of the 
proinflammatory tumor suppressor PDCD4 by the microRNA miR-21. Nat Immunol, 11(2), 141-147. doi: 10.1038/ni.1828

Song, S., Pitot, H. C., \& Lambert, P. F. (1999). The human papillomavirus type 16 E6 gene alone is sufficient to induce carcinomas in transgenic animals. J Virol, 73(7), 58875893.

Stahlhut Espinosa, C. E., \& Slack, F. J. (2006). The role of microRNAs in cancer. Yale J Biol Med, 79(3-4), 131-140.

Stoler, A., Kopan, R., Duvic, M., \& Fuchs, E. (1988). Use of monospecific antisera and cRNA probes to localize the major changes in keratin expression during normal and abnormal epidermal differentiation. J Cell Biol, 107(2), 427-446.

Voronov, E., Shouval, D. S., Krelin, Y., Cagnano, E., Benharroch, D., Iwakura, Y., . . A Apte, R. N. (2003). IL-1 is required for tumor invasiveness and angiogenesis. Proceedings of the National Academy of Sciences, 100(5), 2645-2650. doi: 10.1073/pnas.0437939100

Walboomers, J. M., Jacobs, M. V., Manos, M. M., Bosch, F. X., Kummer, J. A., Shah, K. V., . . . Munoz, N. (1999). Human papillomavirus is a necessary cause of invasive cervical cancer worldwide. J Pathol, 189(1), 12-19. doi: 10.1002/(sici)10969896(199909)189:1<12::aid-path431>3.0.co;2-f

Watson, M., Saraiya, M., Ahmed, F., Cardinez, C. J., Reichman, M. E., Weir, H. K., \& Richards, T. B. (2008). Using population-based cancer registry data to assess the burden of human papillomavirus-associated cancers in the United States: overview of methods. Cancer, 113(10 Suppl), 2841-2854. doi: 10.1002/cncr.23758

Whiteside, T. L. (2008). The tumor microenvironment and its role in promoting tumor growth. Oncogene, 27(45), 5904-5912. doi: 10.1038/onc.2008.271

Yao, Q., Xu, H., Zhang, Q. Q., Zhou, H., \& Qu, L. H. (2009). MicroRNA-21 promotes cell proliferation and down-regulates the expression of programmed cell death 4 (PDCD4) in HeLa cervical carcinoma cells. Biochem Biophys Res Commun, 388(3), 539-542. doi: 10.1016/j.bbrc.2009.08.044

Yao, T., \& Lin, Z. (2012). MiR-21 is involved in cervical squamous cell tumorigenesis and regulates CCL20. Biochim Biophys Acta, 1822(2), 248-260. doi: 10.1016/j.bbadis.2011.09.018

Zhang, J. G., Wang, J. J., Zhao, F., Liu, Q., Jiang, K., \& Yang, G. H. (2010). MicroRNA-21 (miR-21) represses tumor suppressor PTEN and promotes growth and invasion in nonsmall cell lung cancer (NSCLC). Clin Chim Acta, 411(11-12), 846-852. doi: 10.1016/j.cca.2010.02.074

Zhu, S., Wu, H., Wu, F., Nie, D., Sheng, S., \& Mo, Y. Y. (2008). MicroRNA-21 targets tumor suppressor genes in invasion and metastasis. Cell Res, 18(3), 350-359. doi: $10.1038 / \mathrm{cr} .2008 .24$

zur Hausen, H. (2002). Papillomaviruses and cancer: from basic studies to clinical application. Nat Rev Cancer, 2(5), 342-350. doi: 10.1038/nrc798 